\title{
Saúde como Negação da Negação: uma Perspectiva Dialética
}

\author{
FERNANDO LEFEVRE" \\ ANA MARIA CAVALCANTI LEFEVRE
}

Apresenta-se aqui uma visão da saúde e da relação saúde-doença de uma perspectiva dialética, situando o problema no contexto histórico contemporâneo. A problemática é colocada considerando uma tensão entre a visão hegemônica que, de uma perspectiva sincrônica, consiste na produção da saúde tendo como objeto o doente-consumidor. Portanto, implica a reprodução permanente de um sistema produtivo de bens e serviços de saúde e a perspectiva contra-hegemônica que, do ângulo diacrônico e histórico da promoção de saúde e pelo enfrentamento das causas básicas e estruturais do adoecer humano, passe a ler e a enfrentar a relação saúde-doença de modo a ultrapassar a semiologia médica, que tem o doente como objeto, em direção a uma semiologia geral ou semiótica, que tem a doença como seu objeto.

Palavras-chave: Relação saúde-doença; dialética; modelo biomédico; promoção de saúde.

Recebido em: 28/02/2007.

Aprovado em: 15/03/2007. 


\section{Definição prévia de saúde}

A saúde pode, legitimamente, ser vista - não substantiva ou diretamente, como um é... mas, indiretamente, como um sobre... - como um tema de um discurso coletivo, associado a uma prática correspondente, díade situada diferentemente no tempo e no espaço, que tem como objeto um estar/ser positivo de um corpo/mente/espírito, em escala individual e coletiva.

\section{Dois contextos}

Considerado no quadro dos dias atuais e no contexto das formações sociais ditas avançadas, o discurso coletivo da saúde implica uma tensão dialética entre:

- o restabelecimento permanente deste estado/ser positivo, quando o corpo/mente se vê e/ou é visto como ameaçado pela doença;

- a proteção deste ou a vigilância sobre este estado/ser positivo, ambas também permanentes, para que o corpo/mente não seja ameaçado pela doença;

- a produção, igualmente permanente, deste estado/ser positivo, a partir de um grau zero de saúde;

II

- o entendimento e a implantação deste estado/ser positivo pela via da investigação das causas básicas do adoecer humano, visando ou tendo como horizonte a erradicação das ameaças estruturais ao estado/ ser saudável.

Em nosso livro A promoção de saúde como negação da negação (LEFEVRE; LEFEVRE, 2004), definimos o discurso hegemônico da saúde, nas formações sociais contemporâneas, como a produção de um retorno permanente a uma situação de equilíbrio negada pela instalação de uma doença ou agravo, processo que chamamos de negação primária. Essa saúde como negação primária é produtiva, no sentido de que faz parte do sistema produtivo. Mais precisamente, foi-se constituindo e se consolidando, 
historicamente, com o desenvolvimento do capitalismo, como um gigantesco sistema produtivo específico.

Tal sistema produz respostas preventivas e reativas a uma ameaça vista ou representada como insuportável e inadiável, porque ameaça a vida. Isso faz com que a doença acabe também sendo progressivamente vista como a própria razão de ser do sistema produtivo, isto é, como algo da mesma natureza que a fome, um desequilíbrio constitutivo, levando, por isso, à permanente e obrigatória produção do retorno ao status quo ante, na medida em que esse retorno significa a preservação da vida. No discurso hegemônico da saúde, a doença ameaça a vida à medida que aponta para a morte, vista como absoluto. Por isso mobiliza uma reação de defesa igualmente radical visando ao retorno à vida, vista correlativamente como não-morte.

Ao não-morrer biológico soma-se o "não-morrer social”, que é um traço muito característico das formações sociais contemporâneas e que consiste em evitar a todo custo estar doente, que implica a ameaça insuportável de ficar, ainda que por poucos dias, "fora do ar", seja esse "ar" o posto profissional, o cuidado do filho, as contas a serem pagas.

Tudo isso fortalece enormemente o sistema produtivo de saúde como produção preventiva e reativa da não-morte. Mas, além disso, a expansão do "negócio da saúde" levou ao que chamamos de "mais saúde" ou saúde elástica (LEFEVRE; LEFEVRE, 2004), que consiste na oferta abundante e difusa de um sem-número de mercadorias e serviços para consumidores portadores do que poderíamos chamar de "grau zero de saúde" - ou seja, que estão aparentemente saudáveis mas que poderiam estar "mais saudáveis".

Tal prática, no campo da saúde/doença, reflete uma tendência geral do capitalismo contemporâneo, de busca da chamada "desregulamentação" ou liberação de todo tipo de bloqueios ao "livre comércio" (CASSEN, 2007) que, no caso, significa liberar a produção e o comércio de bens de saúde do seu aprisionamento. Ou, como gostam de dizer os neoliberais, de seu engessamento, à doença, tornando mais "flexíveis" (outro ícone da pósmodernidade) e mercadologicamente manipuláveis a relação do mercado com a corporação médica e a relação entre produção de produtos e serviços de saúde e estados prévios de doença ${ }^{1}$. Isso também constitui mais um exemplo do mecanismo geral de "desencaixe" de que falam os teóricos da pósmodernidade (GUIDENS, 1991). 


\section{Dois caminhos}

Partindo-se do axioma de que a doença é um fato, que tem, portanto, uma base real, no contexto I, ou seja, no quadro de uma economia de mercado, tal doença é apropriada e ressignificada como uma fatalidade, sempre renovada na sua forma, que produz efeitos corporais. Estes, por sua vez, geram um sistema de bens e serviços ditos de saúde, entendida esta como o resultado bem-sucedido do enfrentamento direto e da prevenção desses efeitos. No contexto II, tal base real é diversamente ressignificada e o que se busca não são os efeitos, mas as causas básicas das doenças, o que leva a que se deixe de considerá-las como fatalidade.

Considerando o mundo real e histórico das formações sociais contemporâneas, haveria, pois, dois caminhos em disputa, em direção à saúde.

1. O atualmente hegemônico, que consiste em buscar a saúde pelo controle tecnológico da doença. Neste contexto a saúde equivale à busca da cura ou prevenção da doença pela via das tecnologias de intervenção nos corpos e/ou mentes ou nos agentes causadores (entendidos estes como fatores em si, indeterminados). Isso implica, necessariamente, a reprodução ao infinito da sociedade tal como é e se encontra, porque se trata de uma sociedade da tecnologia. Nesta, por definição, não se busca a razão ou causa dos problemas, na medida em que o que se quer é o atrelamento dos indivíduos à necessidade permanente de compra de bens e serviços gerados pela tecnologia, e a busca da causa dos problemas tiraria a própria razão de ser da sociedade de base tecnológica.

A conseqüência desse caminho é que os problemas - no caso, as doenças - continuariam existindo, mas suas consequiências ou efeitos corporais ou mentais nefastos - ou seja, indivíduos ou coleções de indivíduos doentes - estariam cobertos ou permanentemente protegidos pela medicina, vista metaforicamente como um seguro obrigatório.

2. O contra-hegemônico, que implica fugir dessas armadilhas do processo de mercantilização/tecnologização da saúde-doença, abandonandose à "solução tecnológica", ou seja, a busca da saúde pela via da tecnologia. 


\section{Efeito $x$ causa}

De novo, então, duas possibilidades se colocam:

- a conservadora: a doença foi, é e será uma constante, uma fatalidade, e o que nos resta, enquanto humanidade, é enfrentá-la pela tecnologia, controlando, minimizando, evitando sua manifestação nos corpos/ mentes individuais ou coletivos;

- a dialética: doença é e pode não ser, o que significa que o controle tecnológico, com base num modelo biomédico dos efeitos da doença, pode coexistir (em maior ou menor tensão dialética) com a busca das suas causas e com o enfrentamento destas, para que doenças venham a cessar pelo desaparecimento de suas causas.

\section{O deslizamento da doença para o doente}

Hoje, no contexto da hegemonia do modelo biomédico de base tecnológica, verifica-se um permanente deslizamento da doença para o doente, e a doença é entendida e atendida ou, mais precisamente, é entendida-paraser-atendid $a,{ }^{2}$ deslizando e fixando-se, ao final desse processo, na figura cada vez mais individualizada do doente (cada corpo é um corpo, ver o caso dos medicamentos personalizados), objeto da intervenção tecnológica, porque tal doente é também e sobretudo sujeito consumidor desta tecnologia, num mercado de compra e venda de produtos e serviços tecnológicos (medicamentos, cirurgias, exames etc.) ditos de saúde.

\section{Desconstruindo o deslizamento}

A estratégia contra-hegemônica consistiria, então, em enfrentar esse deslizamento, descontruindo-o, desnaturalizando-o. Para tanto há, taticamente, que travar batalhas "miúdas", mas árduas e persistentes, contra as diversas formas que as representações e as práticas hegemônicas relativas à doença e à saúde se revestem no dia-a-dia do funcionamento das formações sociais contemporâneas, buscando sempre revelar suas insuficiências, contradições, as fantasias embutidas nessas representações.

Por exemplo, um modo típico de representação da doença é quando ela aparece como agressão de uma outra bio. Daí parecer natural o fato de 
precisarmos dela nos defender com um antibiótico ou uma vacina ou nos proteger com uma barreira mecânica - como a camisinha, por exemplo. Neste caso, a tática contra-hegemônica poderia consistir, por exemplo, em reescrever essa história para as crianças, nas escolas de ensino fundamental, mostrando que tal história pode ter sido resultado do fato de que nós humanos fomos nos "aventurar" na seara da outra bio e, por isso, seu ataque a nós foi uma defesa, o que pode revelar à criança que a causa da doença pode estar em nós mesmos, seres humanos, enquanto agentes do desequilíbrio ecológico.

Em outro exemplo de história hegemônica, a doença é vista como mau funcionamento ou defeito de uma máquina e prática da saúde, como o conserto da máquina. Neste contexto narrativo, uma máquina é algo que foi feito para funcionar perfeitamente, e se a doença é vista como nãofuncionamento da máquina, este não-funcionamento ou é um defeito irreparável, e então a máquina é jogada fora (=morre), é deixada funcionar pela metade ou é consertada (por intervenção externa e/ou interna, como mudança de comportamento ou estilo de vida). Só existem essas alternativas quando a máquina não funciona. Ora, no quadro dessa metáfora (que não é vista como tal, que é tida como natural) fica muito difícil entender que um defeito nas máquinas possa não ser um problema técnico que nada tenha a ver com erro de projeto da máquina, peça com defeito, desgaste da matéria-prima, entupimento no circuito hidráulico, etc. e sim, por exemplo, com escolhas históricas e coletivas de certos modos de produção em lugar de outros.

Apesar de - sob certo ponto de vista, que é legítimo - o corpo humano poder ser visto como uma máquina que apresenta defeitos de funcionamento e de fabricação que podem ser consertados, etc., por outro lado, como tática contra-hegemônica, pode-se mobilizar o sentimento que todo ser humano tem, de que na sua essência os homens podem ser vistos como máquinas, mas não são, já que máquinas não são seres pensantes ou dotados de vontade. $\mathrm{O}$ conserto de máquinas como modelo de prática de atenção à saúde é, ética e psicologicamente falando, inaceitável, por sua desumanidade e frieza (sendo, aliás, tal desumanidade e frieza uma reiterada queixa da população relativa ao atendimento de saúde).

A mobilização de tal sentimento vem, numa certa medida, sendo praticada entre nós atualmente sob a rubrica da "humanização do atendimento". Porém, a despeito das boas intenções da proposta, cremos que ela, no fundo, é 
apenas uma forma de praticar a técnica com humanidade, "respeito pelo paciente", "paciência" etc., o que equivale por certo a "dourar a pílula".

Desconstruir o atendimento "maquinal" no contexto de uma proposta contra-hegemônica implicaria, portanto, mais do que isso, considerar o paciente como uma verdadeira alteridade, como um sujeito de direito situado no mesmo plano horizontal do técnico, falando de ou sobre o mesmo corpo, mas de outro lugar, do lugar do cotidiano, do lugar do sujeito portador do corpo e da corporeidade, o que pode contribuir para gerar uma relação médico-paciente nova, com negociação de sentidos. ${ }^{3}$

\section{A doença como signo}

Romper, pois, com a doença-que-virou-doente implica passar a considerar - e esta deveria ser a perspectiva da Saúde Coletiva - a doença também como signo. Ou seja, buscar na doença um desarranjo não diretamente dos organismos humanos, mas deles passando pela sociedade. Quando uma doença aparece, não é só um corpo que está doente, a sociedade pode também estar doente; a doença não é sempre algo a ser diretamente tratado no corpo ou bloqueado, controlado, fora do corpo, mas também algo a ser conhecido nas suas raízes.

A doença como signo, isto é, deslocada do doente e alocada na formação social, pode mostrar ou revelar que e onde uma sociedade está errada, desequilibrada. Assim, ver a doença como signo faz parte de um movimento eminentemente dialético quando nega a negação primária, apontando para uma nova síntese - conseqüentemente, para a mudança.

Refletir sobre a doença procurando não seus efeitos nos corpos, mas buscando ir além das causas-dos-efeitos, na direção das causas básicas ${ }^{4}$ do adoecer, significa, pois, usar a doença pedagogicamente porque, por meio dela, a sociedade pode mais facilmente revelar suas mazelas. Mas, para que não se repitam os descaminhos dos apriorismos ideológicos, esta reflexão deve partir, indutivamente, da doença em direção à sociedade, e não dedutivamente, da sociedade em direção à doença.

Com efeito, dedutivamente, acredita-se, apriorística e ideologicamente, porque as sociedades são socialmente injustas e geram pobres, excluídos, miséria, então as doenças devem ser manifestações destes atributos negativos 
previamente conhecidos. Ora, tal postura produz um outro deslizamento: $d a$ doença para a sociedade. É preciso, pois, redirecionar a busca, procurando, indutivamente, a sociedade na doença e não, dedutivamente, a doença na sociedade.

Ver a doença como signo equivale a $l r^{5}$ e pesquisar doenças e não sociedades, mas, diferentemente da medicina, a lê-las e pesquisá-las como coisas que acontecem nas sociedades, ou, mais precisamente, em indivíduos que vivem em sociedades. Então, neste quadro, as perguntas que se colocam são: o que é câncer, diabetes, hipertensão, tuberculose e quem são os indivíduos que adoecem de câncer, de diabetes, de hipertensão, de tuberculose; o que pensam; como vivem; o que comem; onde moram; que histórias de vida têm para contar etc.

\section{O duplo rompimento}

Ver a doença deste modo equivale a um duplo rompimento: de um lado, como vimos, com os apriorismos ideológicos (que é talvez o que em outros tempos se chamou de doença infantil do comunismo...) mas também, de outro, com visão biomédica e tecnológica hegemônica, que tem como base e plataforma o sistema produtivo e o mercado, e que, a partir desta base, entende as doenças como agravos que acometem corpos de clientes/consumidores (diretos ou subsidiados pelo Estado) de serviços e produtos especializados, como atendimentos em consultório, medicamentos, exames de laboratório, etc.

A saúde é, pois, no modelo hegemônico, uma produção (do resultado: restabelecimento do equilíbrio rompido pela doença ou da prevenção do rompimento desse equilíbrio) por parte de um sistema produtivo que, enquanto produção, reproduz a sociedade como conjunto de sistemas produtivos. Por isso, no modelo hegemônico, não pode existir saúde sem doença prévia. De fato, para que haja produção da saúde e reprodução da sociedade produtiva, é preciso que não esteja havendo ou que possa não estar havendo saúde, ou que esteja havendo ou possa estar havendo doença.

Mas o modelo hegemônico não é apenas produtivo, é também orgânico: de fato, o deslizamento da doença para o doente é também um deslizamento para o organismo/máquina, para o doente como organismo/máquina doente. A doença é, pois, nesta linha, um ataque a um organismo, que ameaça sua 
preservação e que mobiliza uma reação e uma prática de produção de defesa, com vistas ao restabelecimento da integridade do organismo, denominada saúde.

O organismo atacado pela doença é um tipo particular de sistema: o sistema circular chamado "vida humana" que, ameaçado, tem que reagir na direção do retorno à situação de equilíbrio pré-ameaça, porque a não-reação seria seu fim (que ironicamente é chamado de êxito letal pela medicina...) - ou seja, a morte ou aquilo que aponta para a morte: sofrimento, dor, invalidez etc.

O modelo contra-hegemônico, por sua parte, nãoé produtivo (pelo menos no sentido de sistema produtivo de bens e serviços derivados da $\mathrm{C} \& \mathrm{~T}$ a serem comprados e vendidos no mercado), nem orgânico, na medida em que não diz respeito ou não tem como objeto, diretamente, a máquina humana chamada "vida", mas a metavida. Esta tem seu lugar não no plano sincrônico do sistema produtivo de base tecnológica, mas no plano diacrônico da História, entendida como sistema aberto, em permanente transformação, para a qual a doença não constitui uma ameaça, mas um desafio, um signo, visto como uma oportunidade de deciframento das ameaças a essa metavida, sendo estas ameaças o que no jargão da saúde coletiva deveria efetivamente ser chamado de causa básica dos processos de adoecimento.

\section{As causas básicas do adoecimento e a promoção da saúde}

Tal deciframento, por seu turno, não deve (como vem acontecendo com certa freqüência) constituir matéria especulativa, na medida em que a metavida, na qualidade de resultante do devir histórico, não é constituída por ideais abstratos que a vida humana deveria buscar, constructos teóricos sobre a boa vida, sobre a vida de qualidade ou a qualidade de vida. É constituída, concretamente, pela tensão dialética entre o que fica dentro do sistema produtivo de saúde circular acima descrito, ou seja, o enfrentamento, pela medicina, dos efeitos das doenças, e o que sobra ou fica fora é o enfrentamento das causas básicas do adoecer.

Com efeito, se o sistema produtivo de saúde foi montado para responder às doenças vistas como ameaças aos organismos humanos, na reprodução desse sistema produtivo só há lugar para as causas-dos-efeitos, e não para as causas básicas do adoecimento, porque a descoberta e o enfrentamento dessas causas básicas tornaria inúteis e ociosos estes sistemas produtivos de resposta (mesmo porque a "pergunta" passaria a ser outra). 
Neste quadro do sistema produtivo de saúde, as causas básicas do adoecimento sobram e é esta matéria sobrante que, na qualidade de signo, precisa ser decifrada. Esse deciframento é, precisamente, a busca da saúde ou o que chamamos (LEFEVRE; LEFEVRE, 2004) de promoção da saúde, ressignificada, a partir de uma perspectiva dialética como negação da negação.

\section{Alguns requisitos para a busca dos determinantes sociais da saúde como tarefa semiótica}

A promoção de saúde, assim entendida, tem a ver com o que vem sendo chamado classicamente, no jargão da Saúde Coletiva, de determinação social do processo saúde-doença e que há pouco entre nós ganhou o status de política pública (COMISSÃO DOS DETERMINANTES, 2007).

Assim, na linha acima proposta, considerando a busca desses determinantes como uma tarefa eminentemente semiótica - uma vez que implica ler, pesquisar e interpretar a doença e suas causas básicas como signos - é necessário partir não do ponto de chegada, que é o social ou a saúde no social, mas do ponto de partida, que são as doenças. Deve-se buscar, em última instância (ALTHUSSER, 1967), decifrá-las não para curá-las, ou controlá-las, ou evitálas ou vigiá-las ${ }^{6}$ mas para, a partir delas encontrar a saúde - ou seja, o enfrentamento e a solução daquilo que na vida particular, coletiva e histórica dos homens faz com que estes adoeçam.

Partir das doenças tendo como horizonte suas causas básicas, ou seja, aquelas que, removidas, promovem a erradicação da doença e, conseqüentemente, a emergência da saúde, pressupõe uma démarche eminentemente orgânico-sócio-histórica, já que implica colocar que as doenças escolhem ou vitimizam certos conjuntos de indivíduos vulneráveis (AYRES, 1997), e não outros. Indivíduos estes que, devidamente inquiridos e contextualizados, podem revelar as sociedades e culturas em que vivem, bem como aspectos da própria história da Humanidade.

De fato, se as sociedades funcionam e se reproduzem por meio dos indivíduos, considerados isoladamente e agregados em grupos, coletividades e classes sociais, é possível, em princípio, resgatar as sociedades como causadoras últimas ou básicas de doenças, a partir desses indivíduos doentes que incorporam e internalizam a sociedade em todos os aspectos de seu funcionamento. É 
possível remontar da doença-nos-indivíduos às causas últimas ou básicas localizadas no núcleo duro do social, que fazem tais indivíduos adoecerem.

Mas, para isso, além de orgânico-sócio-histórica, tal démarche precisará se constituir também em démarche política. Com efeito, se tal remontagem permanecer na qualidade de ato meramente cognitivo, tarefa intelectual e acadêmica, tenderá rapidamente a se esterilizar. Deve então, por isso, para constituir iniciativa fecunda e permanente, buscar aliados sociais que tenham interesse prático nesse resgate e que são, evidentemente, os indivíduos, grupos e comunidades mais diretamente afetados pelas diversas doenças.

No entanto, é claro também que a atuação política referida precisa ter como base norteadora e finalística da ação um modelo e projeto de sociedade alternativa não-geradora de doença. $\mathrm{Na}$ ausência de tal base norteadora, a ação empoderadora estará sempre conduzindo à reprodução dos traços essenciais da sociedade presente, corrigindo, na escala individual dos comportamentos e na coletiva das políticas específicas e setoriais, desajustes e imperfeições no funcionamento da vida social, supondo-se que as doenças estariam ligadas a ou causadas por esses desajustes e imperfeições. Por isso, o processo desse empoderamento terá que vir junto com uma estratégia gradualista de mudança social.

\section{A desfatalização da doença e a destecnologização da saúde}

Por tudo isso, não faz sentido buscar a saúde num passado idealizado de um suposto paraíso ou Jardim do Éden perdido, uma vez que as mudanças introduzidas pelo homem (basta pensar na agricultura) são irreversíveis e exigem uma postura não "retro" mas de reequilíbrio, que terá lugar num meio-ambiente definitivamente científico-tecnológico, como assinala Milton Santos (1996).

Assim, é preciso fugir das armadilhas presentes nas mais diversas propostas que hoje identificam saúde com o "natural" (e a doença com o "artificial") - entendendo-se este natural como tudo aquilo que brotaria diretamente da natureza, sem o concurso humano - e dirigir os esforços para a História, para a Diacronia e para a mudança nas relações do homem contemporâneo com tudo que o cerca (que inclui, evidentemente, os outros homens, ou seja, as chamadas "relações humanas"), objetivando, a um só tempo, a desfatalização da doença e a destecnologização da saúde. 
De fato, para fazer a saúde avançar, é preciso, como se assinalou acima, romper com a representação-mãe e com todas as representações afiliadas, que instituem a saúde como um conjunto determinado de produtos/serviços gerados por um sistema produtivo específico de base tecnológica, montado e permanentemente reproduzido em caráter permanente, como estrutura para responder a uma doença entendida como fatalidade.

\section{À guisa de conclusão: o segredo da saúde está na doença}

O segredo da saúde está, pois, na doença ou, mais precisamente, em jamais desvincular saúde de doença (fora da doença, a saúde tende, inevitavelmente a ser tudo, ou o saco-sem-fundo da qualidade de vida...). Esta é entendida de uma perspectiva eminentemente sócio-histórica, como aquelas marcas, no corpo e na mente, de uma organização imperfeita da vida social, a serem pesquisadas, entendidas e enfrentadas, no plano diacrônico da experiência histórica acumulada do ser humano, partindo sempre, metodologicamente, da doença para a sociedade, jamais no caminho inverso.

Tal entendimento, contudo, precisa coexistir, ainda que em conflito, com o enfrentamento da doença no plano sincrônico e imediato das ameaças ao organismo/mente, que, por serem de morte, dor e sofrimento, são sempre graves e emergentes, precisando, portanto, ser consideradas.

A GRANDE doença nos ameaça, a nós todos, sem distinção, Homens Menores, seres da vida finita e do medo que somos, com a perspectiva da morte, dor, sofrimento. Por isso, estaremos sempre dispostos a financiar, com nossos salários, públicos ou privados, a indústria da saúde, do seguro-saúde e, dentro do chamado campo sanitário, a tecer e entreter, eternamente, esse infinito "bordado de Penélope" da suposta "melhor forma" de organizar, administrar, gerenciar e regular este seguro-contra-o-medo.

A única alternativa, portanto, para buscar e talvez encontrar a saúde, está em entendermos por que persistimos em adoecer - quando isso, como nos assinala Marcuse, em Eros e civilização (1968), não é mais (tão) necessário - lançando mão do Homem Maior da experiência histórica acumulada (que para alguma coisa deveria servir...). 


\section{Referências}

ALTHUSSER, L. Dialética e Ciências Sociais. Rio de Janeiro: Zahar, 1967. AYRES, J. R. C. M. Vulnerabilidade e Aids: para uma resposta social à epidemia. Boletim epidemiológico CRT-DST/AIDS, CVE, São Paulo, ano XV, n. 3, p. 2-4, 1997.

BOURDIEU, P.; PASSERON, J.C. La Reproduction. Paris: Les Éditions de Minuit, 1970.

CASSEN, B. Ponta de lança do neoliberalismo. Disponível em http:// diplo.uol.com.br/2007-01a1488. Acesso em 12 mar. 2007.

COMISSÃO DOS DETERMINANTES. Disponível em http:// www.determinantes.fiocruz.br. Acesso em 12 mar. 2007.

GUIDDENS, A. As conseqüências da modernidade. São Paulo: Unesp, 1991.

LEFEVRE, F.; LEFEVRE, A. M. C. Promoção de saúde: a negação da negação. Rio de Janeiro: Vieira e Lent, 2004.

MARCUSE, H. Eros e civilização. Rio de Janeiro, Zahar, 1968.

SANTOS, M. Técnica, espaço e tempo. Globalização e meio técnico científico informacional. São Paulo: Hucitec, 1996.

SILVA, W. M. Navegar é preciso. Dissertação (Mestrado em Saúde Pública) - Universidade de São Paulo, São Paulo, 2006.

\section{NOTAS}

- Doutor em Saúde Pública; professor titular na Faculdade de Saúde Pública da USP. Endereço eletrônico: flefevre@usp.br.

- Doutora em Saúde Pública; diretora do Instituto de Pesquisa do Discurso do Sujeito Coletivo. Endereço eletrônico: ana@ipdsc.com.br.

\footnotetext{
${ }^{1}$ Nesse sentido é exemplar a criagão, pelo mercado, em associação com segmentos da corporação midica, da "doença" disfunção erectil para justificar a venda para pessoas normais e sadias de potencializadores da ereção, o que reflete uma tendência deste mercado para questionar o monopólio ou a autoridade social (BOURDIEU, 1970) exercido pela corporação médica sobre a definição do que é e não é doença.
} 
${ }^{2}$ Nesse sentido é ilustrativo um padrão persistente de "celebrar" na mídia o surgimento de uma nova "explicação" para uma doença, acoplada à tecnologia, produto, serviço cujo consumo evitaria doença assim explicada. Quem ainda não viu uma noticia de jornal redigida mais ou menos (trata-se aqui de uma ficção) nestes termos: "Pesquisadores japoneses descobriram que a doença $\mathrm{x}$ está associada ao excesso da presença da proteína y no organismo; o laboratório z anuncia para breve a comercialização de um medicamento, hoje conhecido pela sigla PRg7, que combate os efeitos maléficos deste excesso de proteínas no organismo".

${ }^{3} \mathrm{O}$ trabalho de Silva (2006) sobre a influência da Internet na relação médico-paciente é, entre outros, um exemplo interessante dessa tendência.

${ }^{4}$ Evidentemente, os termos "causa dos efeitos" e "causas básicas" estão sendo empregados aqui num contexto sociológico de explicação.

${ }^{5} \mathrm{E}$, por isso, o sujeito dessa leitura deve ser mais um sanitarista em busca da sociedade do que um cientista social em busca do "sanitário".

${ }^{6}$ É curioso e deprimente verificar como, de um modo geral, a esquerda sanitária adota acriticamente essas metáforas tão claramente de direita.

\section{Health as Negation of a Negative: A Dialectic Perspective}

This paper presents a view of health and of health-disease relationship based on a dialectic perspective, placing the problem in the contemporary historical context. The issues consider a tension between the hegemonic view that, from a synchronic perspective, means health production, whose object is the sick one-consumer. So it implies the permanent reproduction of a system that produces health goods and services, and the counter-hegemonic perspective, which, from the diachronic and historical viewpoints of health promotion, and tackling the basic causes of human sickening, starts reading and facing the health-disease relation, in order to overcome medical semiology, whose object is the sick person, towards a general or semiotic semiology, whose object is disease.

Key words: Health-disease relation; dialectic; biomedical model; health promotion. 